VARIA 



\section{(c) $(7)(9)$}

Esta obra está bajo una licencia Creative Commons 



\title{
ESCENAS DEL MITO DE ODISEO EN EL PLUTO DE ARISTÓFANES: DOS EXEMPLA MÍTICOS
}

\author{
SCENES FROM THE MYTH OF THE ODYSSEY IN PLUTUS BY \\ ARISTOPHANES: TWO MYTHIC EXEMPLA
}

\section{Elisa Guevara Macías}

\begin{abstract}
RESUMEN
La presente ponencia estudia dos exempla míticos de temática odiseica en el Pluto de Aristófanes, los cuales aparecen en el discurso desarrollado por el esclavo Carión. Por ello, primero se estudia la disposición de las partes de acuerdo con la retórica clásica. Seguidamente, se analiza los exempla desde su contenido narrativo dentro de la argumentación elaborada por Carión y en la refutación del coro, tomando en consideración la inversión carnavalesca. Finalmente, se menciona brevemente la función de estos exempla en la comicidad, se abordan las expresiones obscenas (escatológicas y sexuales), la parodia y la distorsión mítica, para evidenciar la funcionalidad de estos dentro de la obra.

Palabras clave: exemplum, Odiseo, retórica, parodia, distorsión mítica.
\end{abstract}

\begin{abstract}
This paper studies two mythological exempla from the saga of Odysseus in Aristophanes' Plutus, which appear in the speech made by the slave Carion. Therefore, the first part of this study considers the speech's disposition according to the Classical Rhetoric. Next, analyzes the exempla from its narrative content within the argument made by Carion and the refutation of the choir, considering the carnavalesque inversion. Finally, we briefly describe the function of these exempla in the comedy, considering the obscene expressions (scatological and sexual), mythical parody and mythological distortion, to thereby demonstrate the functionality of these within the play.

Key words: exemplum, Odysseus, rhetoric, parody, mythological distortion.
\end{abstract}

\section{Introducción}

En el Pluto de Aristófanes, Crémilo encuentra al dios Pluto vagando por las calles. Este había sido cegado por Zeus, para que no pudiera discernir entre los hombres justos e injustos y como resultado, los injustos eran ricos, mientras que los justos pobres. Crémilo decide

Lic. Elisa Guevara Macías. Universidad de Costa Rica. Profesora del Departamento de Filología Clásica. Escuela de Filología, Lingüística y Literatura. Costa Rica.

Correo electrónico: elisa.guevaramacias@ucr.ac.cr

Recepción: 17- 11- 2015

Aceptación: 05- 01- 2016 
ayudar al dios a recuperar la vista, de modo que este lo favoreciera con riquezas. Para lograrlo ordenó a Carión, su esclavo, buscar otros trabajadores pobres como él, con el fin de que estos colaboraran en la tarea.

Al principio, los trabajadores se presentan reacios a acompañarlo, como lo demuestran repetidas refutaciones, pero Carión logra finalmente persuadirlos con su argumentación. En esta parte del discurso, Carión utiliza dos exempla míticos referentes a la saga de Odiseo: los encuentros con el Cíclope (vv. 290-301) y con Circe (vv. 302-315), objeto de estudio presente.

Para analizar estos dos exempla mythica, primero se estudia el discurso de Carión en sus partes y disposición a partir de la retórica clásica. Se toma como base las partes expuestas en Retórica de Aristóteles: prooímium, prosthesis, pístis y epílogo; pero en ciertos casos, para enriquecer el análisis, se complementa con información adicional de la Retórica de Alejandro. Después, se analiza los dos exempla desde su contenido narrativo dentro de la argumentación elaborada por Carión y la refutación del coro, tomando en consideración la inversión carnavalesca. Por último, se menciona brevemente la función de los exempla en la comicidad, considerando las expresiones obscenas (escatológicas y sexuales), la parodia y la distorsión mítica, para evidenciar su cometido dentro de la obra.

\section{Disposición de discurso de Carión}

El discurso de Carión se desarrolla entre los versos 253 y 321, pero el coro interviene diez veces en un total de 31 versos, por lo que el discurso propiamente dicho tiene una longitud de 37 versos. El Pluto de Aristófanes al ser una comedia, por definición es dialógica; por ello, el discurso de Carión no se desarrolla de manera íntegra, sino que se ve frecuentemente interrumpido por la participación del coro. Aun así, la disposición del discurso y sus respectivas partes pueden ser identificables.

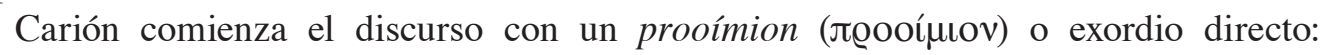
"Amigos y paisanos, laboriosos agricultores que tantas veces habéis comido ajos con mi señor, venid, apresuraos, corred, no hay que perder un instante, acudid en nuestro auxilio"1 (vv. 253-6). Con ello, busca la atención de los trabajadores y su benevolencia. Siguiendo la Retórica a Alejandro $(29,1)$, el prooímion se emplea para lograr de manera inmediata que el receptor atienda. Su objetivo es preparar a los oyentes, conseguir su atención e interés y captar su benevolencia, al mismo tiempo que se expone brevemente el asunto a tratar. Este propósito finalmente se cumple cuando Carión les revela la causa de este llamando: “[...] Mi dueño quiere anunciaros que en adelante nadaréis todos en la abundancia, libres de esa vida ruda y miserable" (vv. 261-3).

Ante la revelación, el coro se presenta dudoso e incrédulo, por lo que piden mayor información sobre la noticia. Para esto, Carión narra al coro la presentación de Pluto ante su amo y la pobre apariencia del dios: "Se ha presentado aquí, mis pobres amigos, con un viejo sucio, encorvado, miserable, calvo, lleno de arrugas, sin dientes, y, por Júpiter, creo que hasta circuncidado" (vv. 265-7).

La narración de Carión es clara, breve y verosímil, por lo que logra presentar a este anciano de manera convincente, tanto así que inmediatamente el coro lo reconoce como Pluto, dios de las riquezas. Sin embargo, a pesar de que la narración es convincente, el coro piensa que Carión los está engañando: "CORO.- ¿Crees que si nos engañas te vas a ir impune, teniendo yo un garrote en la mano? CARIÓN.- ¿Por tan desvergonzado me tenéis que me juzgáis incapaz de hablaros formalmente?" (vv. 271-4). 
El discurso de Carión no está logrando su objetivo: persuadir al coro de trabajadores de acompañarlo; y ello se debe a una razón fundamental: la falta de talante de Carión. De acuerdo con Aristóteles (Retórica I, 5), dentro de las pruebas de persuasión propias del arte

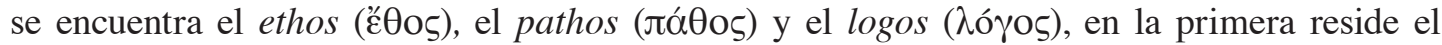
talante del que habla, en la segunda la predisposición al oyente de alguna manera (por medio de las emociones generalmente) y, en la última, se encuentra el discurso mismo, lo que este demuestra o parece demostrar. Por supuesto, la proposición de hacerlos ricos es un argumento (logos) bastante persuasivo; sin embargo, el ethos, el talante o carácter de Carión, no lo es. Precisamente, su pregunta retórica lo cuestiona, sin embargo, Carión es esclavo y, por ello, carece de toda credibilidad.

Este hecho conlleva a una disputa entre Carión y el coro, que solamente logra ser superada gracias a que este último recuerda que el esclavo es un enviado, un mensajero de su amo, quien por su parte, sí es digno de crédito. Así, Carión regresa a su discurso y revela la

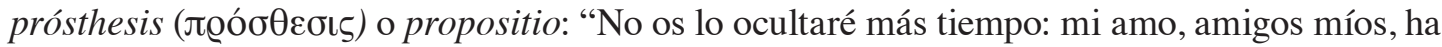
venido con Pluto en persona, que os enriquecerá” (vv. 284-6). El coro pregunta: “De verdad seremos todos nosotros ricos?"; a lo cual Carión responde por medio de un exemplum: "Sí, por los dioses, ciertamente seréis unos Midas, si os salen unas orejas de burro" [traducción propia] (v. 287).

Siguiendo a Aristóteles (Retórica I 2,7), el exemplum (parádeigma) se basa en una relación de semejanza, de la parte con la parte o de lo semejante con lo semejante, especialmente cuando se dan dos proposiciones del mismo género, pero una es más conocida que la otra. Ello es evidente en caso de la argumentación de Carión, que primero ofrece la proposición y luego lo respalda con la mención a Midas, rey de Frigia, prototipo de riqueza. Según el mito, Dionisio lo recompensó por la hospitalidad que este tuvo con Sileno, quien fue capturado en los jardines ${ }^{2}$ del rey (Heródoto, Historia VIII, 3). A petición de Midas, el dios le otorgó el don de convertir todo lo que tocase en oro, por ello es el prototipo de la riqueza.

Asimismo, Carión alude a otro episodio del mito de Midas, el cual relata que el rey juzgó la destreza musical de Apolo y Pan (Marsias, en otras versiones), otorgándole la victoria a este último, por lo que el enfurecido dios en castigo hizo que le creciesen orejas de asno.

Este exemplum no solo tiene la función de embellecer el discurso (ornatus), sino que su fin principal es persuadir al coro de trabajadores, pues, siguiendo a Aristóteles (Retórica I 2, 4), el ejemplo o paradigma es una prueba demostrativa de la pístis ( el exemplum debe utilizarse fundamentalmente como recurso o figura de amplificación dentro de la argumentación y por supuesto, de la pístis, lo cual en el discurso de Carión se logra a través de la mención de Midas, que a su vez también es una hipérbole y, por ende, una amplificación de la proposición, pues el coro será tan rico que podrá convertir todo en oro.

Ante este argumento, el coro reacciona de manera muy positiva: “¿Qué alegría! ¡Qué placer! Voy a bailar de gusto, si es verdad lo que dices" (vv. 288-9). Precisamente, es a partir de este verso que comienza el canto coral, en el cual Carión utiliza dos episodios propios del mito de Odiseo, específicamente del nostos, primero el episodio del Cíclope (vv. 290-301) y luego el de Circe (vv. 302-315). La utilización de estos dos episodios no es casual, Carión se proyecta como líder del coro y guía de su baile, semejante al Cíclope con sus rebaños y a Circe con la piara de cerdos. No obstante, el coro refuta cada ejemplo siguiendo el hilo narrativo del mismo, lo cual colabora y refuerza la uis comica.

Finalmente, después de la exposición de ambos exempla y las respectivas refutaciones del coro, Carión termina el canto coral con un breve epílogo: “¡Ea, cesen los jocosos insultos! 
Entonad otro género de versos. Yo voy a entrar en casa y a coger, a escondidas de mi amo, un poco de pan y carne; en cuanto lo coma volveré al trabajo" (vv. 316-321).

Siguiendo a Aristóteles (Retórica III 18,3), “el epílogo consiste en cuatro puntos: inclinar al auditorio a favor y en contra del adversario; amplificar y minimizar; excitar las pasiones en el oyente; y hacer que recuerde" (Aristóteles, 1990, p. 593-4). La conclusión del discurso de Carión no cuenta con estas características, por lo que no se trata de un epílogo eficaz. Adicionalmente, el comentario final sobre su intención de robarle comida a su amo recalca su falta de talante y credibilidad (ethos). No obstante, esto no perjudica el propósito del discurso, pues el objetivo ya se ha logrado, se persuadió al coro de marchar con él en ayuda de Crémilo. La apatía hacia Carión se hace evidente en las dos refutaciones a los exempla míticos, como se verá a continuación.

De esta manera, el discurso de Carión presenta las cuatro partes expuestas por Aristóteles: prooímium (vv. 253-6, 261-3), prósthesis (vv. 284-6), pístis (v. 287, 290-5, 302-8) y epílogo (vv.316-21). Presentadas así las partes del discurso, corresponde pasar al análisis de los exempla de temática odiseica que se encuentran entre los versos 290 y 315.

\section{Análisis del contenido narrativo de exempla míticos}

Aristóteles (Retórica II 20, 1) distingue dos especies de ejemplos o paradigmas ( $\pi \alpha \varrho \alpha ́ \delta \varepsilon เ \gamma \mu \alpha)$ : "una especie consiste en referir un hecho que ha sucedido antes y, la otra, en inventarlo uno mismo". El primero remite a narraciones históricas, mientras que el segundo a las ficticias. Los exempla míticos pertenecen a la segunda especie, pues en el contexto de Aristóteles y de Aristófanes, los relatos míticos se utilizan como motivos de creación poética (cf. Aristóteles, Poética). Aunque se alteren, se varíen o se inviertan ciertos detalles, estas narraciones están formadas por elementos esenciales, que las hacen reconocibles. Precisamente, esto sucede en los exempla míticos utilizados por Aristófanes.

A partir de la intervención del coro en los versos 288-9, se inserta un tema secundario en la argumentación: el liderazgo de Carión como guía del coro. La proposición es rechazada por el coro, lo que comienza una disputa, que se desarrolla a partir del verso 296. Aunque, los intentos por persuadir al coro fracasan, los exempla míticos utilizados en la demostración son muy interesantes. Primeramente, Carión emplea la figura del Cíclope, como pastor de rebaños:

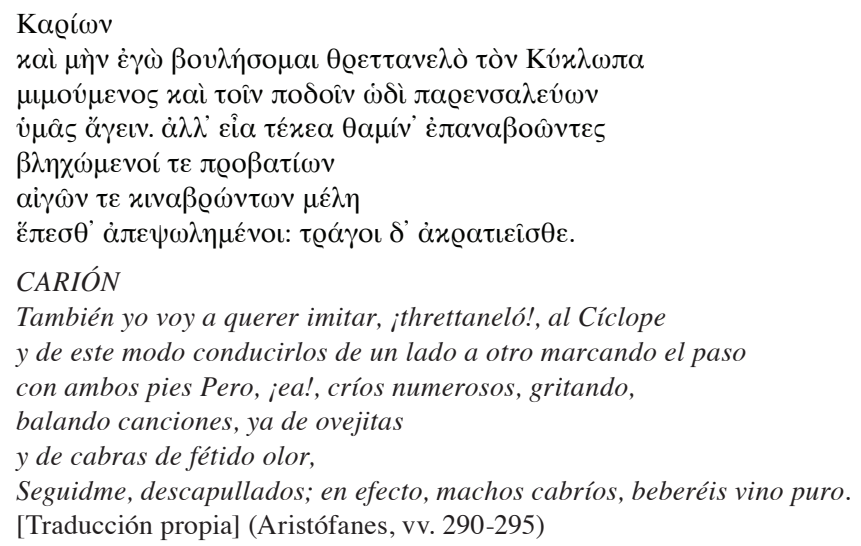

El primer detalle que destaca es la elección del Cíclope, en lugar del héroe, como protagonista. La identificación de Carión con el antagonista es un elemento de inversión, como lo ha señalado Roberto Morales Harley (2013, p. 56): 
En la primera estrofa, la inversión es completa: el papel protagónico no recae sobre Odiseo o sus compañeros, encarnados por el Coro, sino sobre el Cíclope, representado por Carión; y el cíclope no es un personaje bárbaro, sino que ofrece muestras de dominar los elementos culturales propios del festejo, el baile y el canto.

La caracterización del Cíclope conduciendo al son de la lira a sus rebaños, como lo

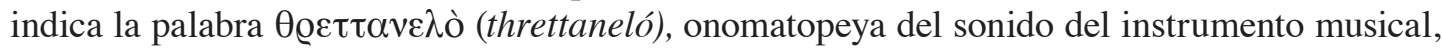
es una variación de la versión tradicional del mito, que presenta un Cíclope salvaje, monstruoso e incivilizado. Por ello, Aristófanes utiliza una versión muy particular, la cual no tiene como referente la narración homérica, presente en la Odisea; sino que se trata de una parodia directa del Cíclope de Filóxeno de Citera (435-380 a. C.), conocido dramaturgo contemporáneo del comediógrafo. Se sabe que en este novedoso ditirambo, Filóxeno representaba de manera muy original el encuentro de Odiseo con el Cíclope, pues incluía el episodio amoroso de Polifemo y Galatea dentro de la trama (fr. ${ }^{3} 83,84,87$ ). Debido a ello, la obra contempla una

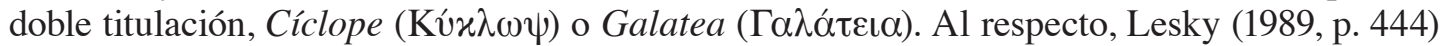
menciona que "en el ditirambo Cíclope se relataba la aventura de la Odisea [...], pero el motivo más sugestivo lo constituía el amor del torpe monstruo por la delicada nereida Galatea, que aprovechó Ulises astutamente para procurarse la salvación”.

Solo se conservan diez pequeños fragmentos (fr. 81-91) que no logran dar luces suficientes para comprender la interconexión entre el episodio odiseico y el relato amoroso, ${ }^{4}$ por lo que se ignora su tratamiento. En la obra de Aristófanes, no se incluye este elemento, pero sí la particular caracterización del Cíclope.

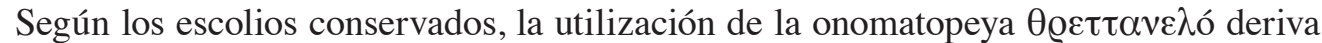
de la obra de Filóxeno, así como el verso 292 es una parodia verbal, tomado directamente de este ditirambo (85). Ello indica que el coro del ditirambo estaba conformado por el rebaño del Cíclope que bailaban al ritmo de la lira de su amo, como lo presenta Aristófanes.

Siguiendo a Sancho-Royo (1983, p. 45), Filóxeno fue uno de los instauradores del nuevo ditirambo, que tenía como característica primordial la superación de la tradición anterior por medio de nuevas manifestaciones musicales, que en su época fueron ampliamente criticadas por los comediógrafos, entre ellos Aristófanes. Por tal razón, se hace hincapié en el elemento musical y en el canto, especialmente del coro que debe gritar balidos de ovejas y cabras.

Otra cuestión interesante es la conformación del rebaño, donde la inversión es

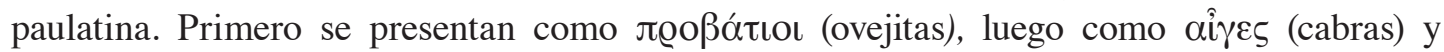
finalmente, como t@áyol (machos cabríos), con lo cual inversión está completa junto a la alusión dionisiaca de la toma de vino puro. En realidad, esto puede ser interpretado como una amenaza para el coro, pues de acuerdo con el mito, el héroe ofrece vino puro al Cíclope para emborracharlo y, una vez dormido, cegarlo.

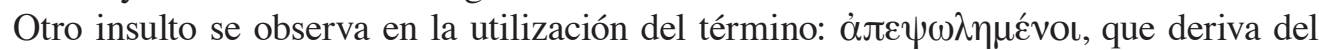
verbo $\dot{\alpha} \pi 0 \psi \omega \lambda \hat{\varepsilon} \omega$, cuyo significado es praeputium retrahere alicui (Lidell y Scott, 1940, p. 229). Aristófanes lo utiliza en participio perfecto medio en vocativo masculino plural, por lo que denomina directamente al coro. Se trata de un verbo compuesto por el prefijo ájo-, que puede ser traducido como aparte, lejos, sin; mientras que la raíz está emparentada con el sustantivo $\psi \omega \lambda$ ós, ov̂, ò, que también es de difícil traducción. De acuerdo con Liddell y Scott (1996, p. 2029), este término puede ser entendido como with the prepuce drawn back, mientras que en femenino $\psi \omega \lambda \eta \dot{~ e s ~ m e m b r u m ~ v i r i l e ~ p r a e p u t i o ~ r e t r a c t o . ~ P o r ~ l o ~ t a n t o, ~ e s t o s ~}$ términos remiten a la acción de retirar el prepucio del pene, dejando expuesto el glande, ya sea por circuncisión o por retracción natural, generalmente por erección. Entre los griegos dicha 
acción es considerada vergonzosa y grosera, por lo que no es de extrañar que Aristófanes la utilice frecuentemente ${ }^{5}$ como insulto o elemento sexual lascivo.

En francés, Blanc y Lamberterie (2009) utilizan la palabra déprépucé para transmitir el significado más preciso. En español, el término $\psi \omega \lambda$ ós es traducido tradicionalmente como "circuncidado", lo cual aplica dependiendo del contexto. Por ejemplo, este término es apropiado en Pluto (v. 267), cuando se describe al dios como un anciano decrépito sin dientes y circuncidado.

En el caso de concepto $\alpha \operatorname{\tau o} \psi \omega \lambda \varepsilon \dot{\varepsilon} \omega$, este aparece registrado seis veces ${ }^{6}$ en Aristófanes y por lo general se traduce como descapullar, ${ }^{7}$ para así diferenciar el acto de retracción natural

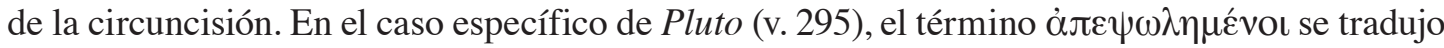
como 'descapullados', pues no remite a la circuncisión, sino a la retracción natural del prepucio, posiblemente por erección. Ello se justifica por la utilización consecutiva de đ@áyou (machos cabríos), que en contexto dionisiaco son identificables con los sátiros, seres que en el teatro, especialmente en los dramas satíricos, se representaban itifálicos. ${ }^{8}$

La identificación del coro con sátiros dentro de la representación del episodio odiseico no es una novedad, pues ello sucede en el Cíclope de Eurípides, único drama satírico que ha llegado de manera íntegra hasta la actualidad. Sin embargo, en Aristófanes, el coro está compuesto por el rebaño y no por sátiros propiamente dichos, la identificación viene dada por la alusión, que de hecho funciona como elemento de inversión.

En el caso de la refutación del coro, la inversión es también un elemento recurrente. En la estrofa, el coro fue identificado con el rebaño; pero aquí él mismo se equipara con Odiseo, pues amenaza con cegar a Carión mientras duerme, como lo hiciera el héroe con el Cíclope en el relato mítico:

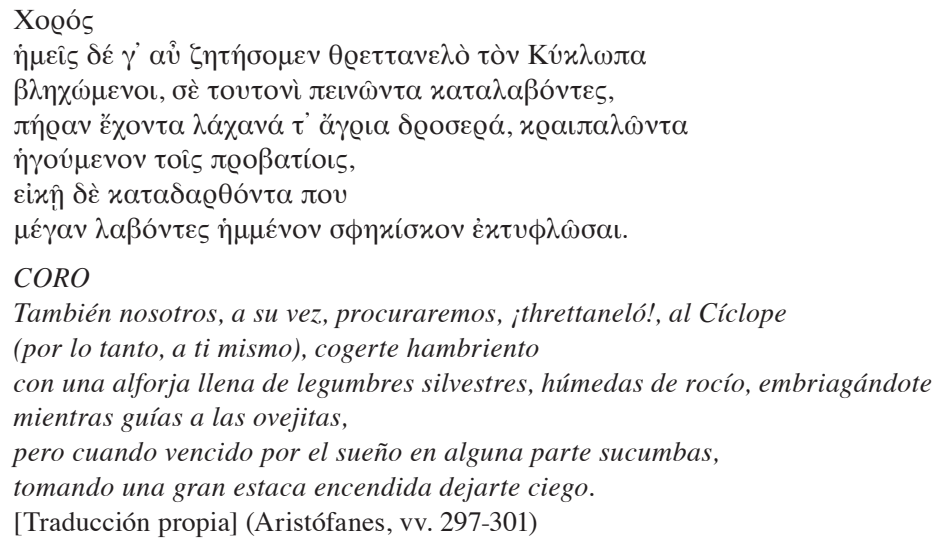

En la primera antistrofa del canto coral, se hallan varios elementos coincidentes con la tradición homérica: la estratagema del vino para emborrachar al Cíclope (Od. IX, 345-374) y el sucesivo cegamiento con la estaca incandescente (Od. IX, 318-335, 375-394). No obstante, se observan otros elementos ajenos a la tradición. En primer lugar, la mención del sonido de la lira, que se debe directamente a la parodia de la obra de Filóxeno. En segundo lugar, destaca la pretensión del coro de emborrachar a Carión mientras come, como sucede en la versión homérica; sin embargo, aquí se presenta un Cíclope que se alimenta de legumbres y verduras silvestres. Ello es una inversión completa en relación con el relato mítico tradicional, donde el Cíclope devora a los compañeros del héroe. 
El cambio del canibalismo al vegetarianismo es una característica que podría haber estado en la obra de Filóxeno, sin embargo, ello se desconoce; por lo que podría tratarse de un elemento de comicidad, implantado en el relato por Aristófanes.

La refutación precisamente se encuentra en el cambio de la identificación del coro con el personaje mítico de Odiseo en contraposición al coro de animales que evidentemente es una denigración de carácter y, por ende, un insulto. Ello se repite en la segunda estrofa, cuando Carión toma como ejemplo la metamorfosis de los hombres en animales a manos de Circe:

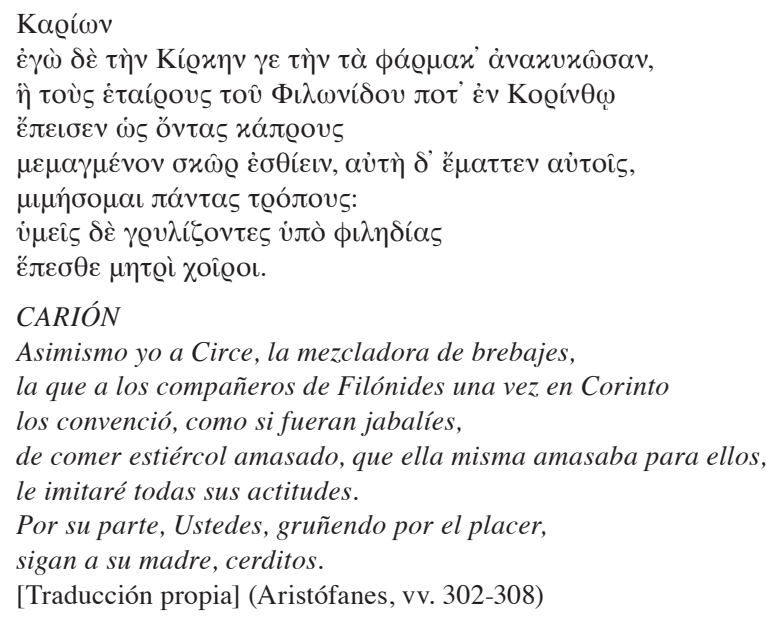

Nuevamente, se observa un distanciamiento con respecto al relato mítico, aunque hay elementos narrativos tradicionales: Circe como hechicera y la metamorfosis de los hombres en animales. No obstante, hay muchas divergencias. En primer lugar, según el comediógrafo, Circe se localiza en Corinto (v. 303), zona donde previamente en la obra se señala como lugar de procedencia de prostitutas (v. 149), lo cual está relacionado directamente con la mención de Filónides, ${ }^{9}$ pues este personaje se encontraba involucrado con Lais ${ }^{10}$ (v. 178), una famosa hetaira de la época. De esta manera, indirectamente se relaciona a Circe con la figura histórica de Lais, con lo cual se amplifica la inversión carnavalesca.

Bracke (2009, p. 160) explica que “in Aristophanes' Plutus, Circe is portrayed as dominatrix and whore, on the one hand able to transform men magically into swine, and, on the other hand, a victim to Odysseus' lust"11. La analogía con Lais potencia el carácter cómico de la alusión al episodio de Circe, pues distorsiona el relato mítico; Aristófanes crea una analogía entre la metamorfosis de los compañeros de Odiseo y el deseo lujurioso, como Lais perdió a Filónides, el poder mágico de la diosa se asemeja al poder seductor de la prostituta.

Por otra parte, los hombres son "convencidos" de ser xát@ou (jabalíes) (v. 304) y "de comer estiércol amasado, que ella misma amasaba para ellos" (v. 305). En la versión homérica, ella los alimenta con bellotas de encina, hayuco y frutos de corneja (Odisea, X, 242). Las menciones escatológicas son una inversión carnavalesca que tiene como característica lo bajo corporal y lo grotesco, habitual en el género cómico.

Por último, en la segunda estrofa del canto coral, se utiliza burlescamente el término

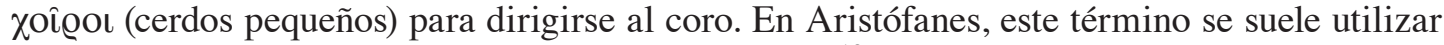
de manera metafórica para referirse al sexo femenino ${ }^{12}$ (pudenda muliebria), que además se ve relacionado con mención del placer (i்ò $\phi ı \lambda \eta \delta i ́ \alpha \varsigma)$. Por tal razón, nuevamente se trata de otra alusión bajo corporal, en este caso de carácter sexual. 
Existe una relación entre la primera estrofa y la segunda. En ambas se alude a órganos sexuales, primero el masculino y luego el femenino. El primer insulto se intensifica en la segunda estrofa como respuesta a la refutación del coro. Asimismo, ante el exemplum utilizado por Carión, el coro continúa la analogía diciendo:

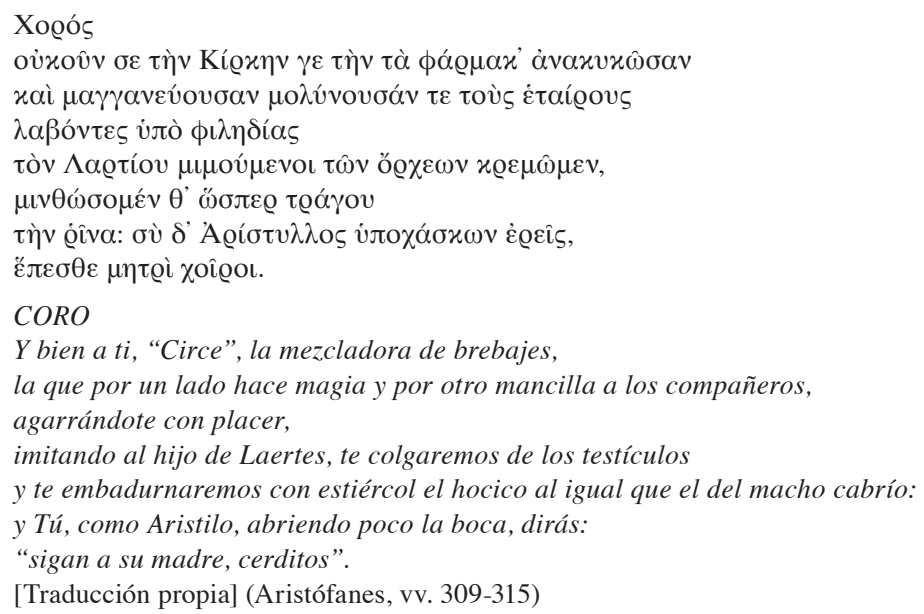

Nuevamente el coro se identifica con el héroe, pues afirma que imitará al hijo de Laertes, es decir, a Odiseo. De la misma manera, que en la analogía con el Cíclope, aquí el coro pretende castigar a Carión, identificado con Circe. Otro indicio es la mención del placer (íjò

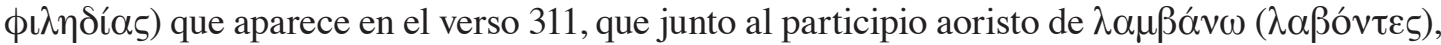
verbo que en este contexto puede ser traducido como 'agarrar', 'tomar', 'coger', 'apoderarse de', enfatizan la idea de captura, que en este caso tiene un carácter sexual.

El elemento más interesante de la refutación del coro es el motivo del castigo. Específicamente dice: "te colgaremos de los testículos y te embadurnaremos con estiércol el hocico al igual que el del macho cabrío" (vv. 312-313). La mención escatológica no es de extrañar, pues responde a la presente en el verso 305. Sin embargo, se trata de una amplificación, pues se menciona a Aristilo, ateniense y contemporáneo del comediógrafo, el cual es ridiculizado por obtener placer de la materia fecal ${ }^{13}$ (Thorburn, 2005, p. 68). De esta manera, el coro replica el insulto de la segunda estrofa y lo intensifica, por medio de la alusión a la coprofilia, atracción fetichista que consiste en la excitación sexual generada por los excrementos. De nuevo, se encuentra el elemento escatológico, pero esta vez unido al aspecto sexual.

Otro punto interesante es la mención de đ@áyos ('macho cabríos') en el verso 313, lo cual relaciona la última antistrofa con la primera estofa (v. 295). En este contexto, la inversión es completa, el vino puro del principio se ha convertido en estiércol.

En el caso del motivo del castigo, no presenta relación con el relato tradicional, presente en la narración homérica, donde el héroe amenaza con la espada a la diosa para asustarla (Od. X 321-22), siguiendo el consejo de Hermes (ibid. 294-95), y no la castiga de ninguna manera. Seguramente, este motivo tiene un origen cómico, por la inversión revelada en el castigo a una divinidad.

De la misma manera que sucede con la escena del Cíclope, posiblemente el exemplum del episodio de Circe es, a su vez, parodia de un texto de la época de Aristófanes, del cual no se tiene noticia, pero que seguramente tenía como tema central este episodio del mito de Odiseo. Suponiendo que el referente para Aristófanes fuera el drama satírico de Esquilo, Di Marco 
(1994), citado por Lucas de Dios (Esquilo, 2008, p. 395), propone que este castigo también habría tenido lugar "en la versión esquílea: Odiseo colgaría a Circe de los pies y la sometería a un castigo semejante al que habían sufrido sus camaradas", de la misma manera que el coro castiga a Carión con estiércol, por alimentar a los suyos con él. Obviamente, esto supondría un

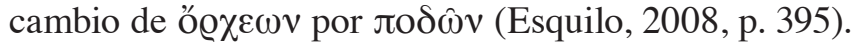

Por su parte, Melero-Bellido (1988, p. 427) propone que la utilización del episodio de Circe puede suponer la existencia de otro ditirambo de Filóxeno dedicado a esta temática odiseica, lo cual relacionaría ambos exempla míticos. De haber existido este poema de Filóxeno, el coro habría estado compuesto por los compañeros del héroe metamorfoseado, como se alude en la parodia aristofánica. Aun así, no se tiene evidencia factible de que este autor tratase este episodio en ninguna de sus obras.

Sea cual fuere el referente de Aristófanes, es probable que la narración mítica del exemplum no provenga directamente de la versión homérica, sino de una fuente distinta seguramente de origen cómico.

\section{La función de los exempla míticos}

La finalidad del discurso de Carión es conseguir que el coro de labradores colabore con su amo en la misión de curar a Pluto de su ceguera. Este objetivo se cumple rápidamente con la promesa de riqueza. En realidad, Carión no presenta argumentos complejos, solamente un exemplum mítico de Midas.

Sin embargo, una vez logrado su objetivo, se inserta un tema secundario en la argumentación, el liderazgo de Carión en la guía del coro, que emocionado ante la idea de ser rico quiere bailar. Carión no es digno de ser el guía del coro, lo cual da comienzo a la disputa, que en realidad es una digresión de la temática central.

En ambos exempla, existe una identificación de personajes Cario-Cíclope-Circe, coro-rebaño-cerdos-Odiseo, lo cual es un componente evidentemente carnavalesco. No solo en inversión del orador, que se identifica con personajes antagonistas y no con el protagonista mítico, sino también en la doble identificación del coro en un caso denigrado por Carión a la forma animal y después resaltado por sí mismo con la caracterización heroica. Esta elección reitera la falta de credibilidad y talante por parte de Carión.

Asimismo, se encuentran múltiples alusiones sexuales y escatológicas, lo cual no es de extrañar, pues son elementos utilizados por el comediógrafo para elevar la comicidad. Luis Gil (1993, pp. 27-28) clasifica los rasgos de la comicidad aristofánica según tres vertientes: intelectual, emocional y social del fenómeno universal de lo cómico. "A la vertiente intelectual corresponde la originalidad, a la emocional el énfasis reiterativo, y al componente social el carácter popular de algunos de sus recursos". Las alusiones escatológicas y sexuales observadas en los exempla míticos anteriores pertenecen al componente emocional, que consiste "en la llamada a impulsos sádicos, sexuales, escatológicos, o en la repetición de la misma situación o de una frase clave" (Gil, 1993, p. 28), como sucede principalmente en la segunda estrofa y antistrofa.

El componente emocional, basado en este caso principalmente en los elementos escatológicos y sexuales, da como resultado la distorsión de ambos relatos míticos, fuentes de los exempla. Asimismo, es importante recalcar que el referente no es el mito tradicional presente en la versión homérica, sino que Aristófanes toma como fuente obras contemporáneas suyas, como sucede con el Cíclope de Filóxeno, pues su finalidad es la parodia, que en la Antigüedad se entiende como la imitación burlesca de formas literarias. 
Siguiendo a Gil (1993, p. 32), ello requiere el conocimiento del modelo imitado y, a su vez, el reconocimiento del público, en sus semejanzas y en sus diferencias, en el remedo paródico. El efecto cómico reside precisamente en la incongruencia: en el modelo referencial, la relación entre forma y contenido es armónica; pero, en la parodia, se rompe conscientemente esa armonía, de tal manera que la expectación del público se viene abajo por los desequilibrios formales (como la utilización de diminutivos u obscenidades) y de contenido (como inversiones carnavalescas).

Ello se evidencia en la analogía del esclavo Carión con el Cíclope y con Circe, pues "en la parodia se aplican predicados elevados a sujetos humildes, lo trivial se expresa en lenguaje grandilocuente" (Gil, 1993, p. 32). En ambos casos, son parodias de situación, ya que se dedican a imitar burlesca o cómicamente la acción mítica presente en el referente, que en el caso del Cíclope se conoce, pero no se tiene la misma suerte con la escena del episodio de Circe. Por su parte, gracias a los escolios conservados, se ha logrado identificar un caso de parodia verbal presente en el verso 292.

En el caso en la distorsión mítica, en esta "se mantiene el contenido de un modelo serio, pero se le reviste de una forma inferior e inapropiada a su categoría; se degrada lo sublime envolviéndolo en formas ridículas y burlescas" (Gil, 1993, p. 36). Al lado de la parodia, se observan elementos tradicionales de la narración mítica; por ejemplo, en la escena del Cíclope se conservan las principales acciones del héroe: la estratagema del vino y el cegamiento, mientras que en el exemplum de Circe se mantienen su caracterización como hechicera y su poder mágico de transformación. Aparte de la utilización de expresiones obscenas y menciones sexuales y escatológicas, la distorsión se encuentra en la caracterización del Cíclope como citarista y vegetariano (que posiblemente es una distorsión presente ya en el referente de Aristófanes), como también en la asociación del coro de ovejas con las acciones del héroe. Por su parte, en el caso del segundo ejemplo se halla en la identificación de Circe con la prostituta Lais y de Odiseo con Filónides.

Por estas razones, estos exempla no tienen mayor relevancia en la argumentación del discurso de Carión, que de hecho no logra persuadir al coro de ser su guía en el baile; sino por el contrario, su valor radica en la obra en general, pues gracias a ellos se logra aumentar la comicidad por medio de la parodia y la distorsión mítica.

\section{Conclusiones}

Recapitulando el estudio en los apartados anteriores, en primer lugar, se demostró que el discurso de Carión presenta las cuatro partes expuestas por Aristóteles: prooímium (vv. 253-6, 261-3), prósthesis (vv. 284-6), pístis (v. 287, 290-5, 302-8) y epílogo (vv. 316-21). El coro decide marchar en ayuda de Crémilo, por el talante de este y por la tentadora prosthesis. También se explicó el papel de exemplum mítico de Midas dentro de la persuasión del coro.

En el caso específico de los dos exempla del mito de Odiseo utilizados por Carión, se demostró que son ampliamente refutados por el coro, pues con ellos se buscaba otro objetivo secundario: persuadir al coro del liderazgo de Carión sobre el baile. No obstante, Carión es rechazado por este, utilizando también el contenido mítico de los ejemplos.

Estos exempla no tienen un papel importante dentro de la argumentación principal del discurso, sino que tienen otra función distinta: la comicidad. Ello se logra esencialmente por medio del componente emocional, basado en el insulto jocoso y las expresiones obscenas (escatológicas y sexuales), pero también a través de la parodia y la distorsión mítica. 
La parodia principalmente se encontró en la identificación de Carión con los personajes antagónicos del Cíclope y de Circe, en lugar de tomar de la figura del héroe, como lo hizo el coro en su respuesta. Otro elemento paródico se halló en las múltiples alusiones al Cíclope de Filoxeno, tanto en parodia de situación como verbal. Posiblemente, también la utilización del motivo del castigo presente en la escena de Circe, sea una parodia de situación, sin embargo, se desconoce el referente.

Por su parte, la distorsión mítica se observa principalmente en el tratamiento de los relatos míticos. En primer lugar, la caracterización del Cíclope, que se presenta como un poeta bucólico que pastorea sus rebaños al son de la lira. En segundo lugar, el cambio del canibalismo al vegetarianismo, por lo que este monstruo se proyecta inofensivo y ridículo en comparación con el personaje terrible de la versión homérica. En el caso de la escena de Circe, la identificación de la diosa con la famosa prostituta Lais, inversión carnavalesca que distorsiona el relato mítico. Ello se incrementa con la asociación del personaje heroico con Filónides, amante de Lais.

De esta manera, se demostró que la finalidad de estos dos exempla míticos es fundamentalmente aumentar y fortalecer la uis comica.

\section{Notas}

1. La mayoría de las citas de la comedia de Aristófanes provienen de la traducción de F. Baráibar y Zumárraga (1954), cuando son de otro autor se indica en el texto.

2. Según Jenofonte (Anábasis I 2, 13), el sátiro se encontraba mezclando vino en una fuente cuando fue descubierto.

3. Para los fragmentos de la obra de Filóxeno se sigue la edición de Page (1967).

4. Para este tema, consúltese los trabajos de Sancho Royo (1983), Sutton (1983) y Hordern (1999).

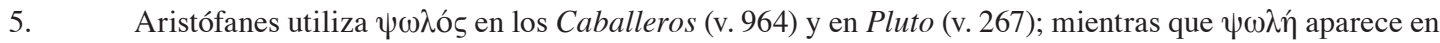
las Aves (v. 560) y en Lisístrata (vv. 140, 978).

6. $\quad$ Lisístrata 1136; Paz 904; Pluto 295; Thesmoforias 1188, Acarnienses 161, 593.

7. Este término es utilizado por Luis Macía Aparicio (Aristófanes, 2007), por Luis Gil (Aristófanes, 2000) y por Francisco Rodríguez Adrados y Juan Rodríguez Somolinos (Aristófanes, 2004).

8. Los actores que interpretaban el papel de los sátiros generalmente utilizaban una indumentaria particular, basada especialmente en una cola, en un falo falso y en el perizoma, una especie de pantalones cortos.

9. Hombre ateniense del siglo $\mathrm{V}$ a. C. fuertemente ridiculizado por los comediógrafos de la época, por su fealdad, grosería, ignorancia y sus amores con Lais (o Nais) (cf. Thorburn, 2005, p. 437).

10. Vivió entre los siglos V y IV a. C. A los siete años fue raptada por un soldado ateniense en Sicilia y vendida en Corinto como esclava, se convirtió en prostituta (cf. Thorburn, 2005, p. 307).

11. In Aristophanes' Plutus, Circe is portrayed as dominatrix and whore, on the one hand able to transform men magically into swine, and, on the other hand, a victim to Odysseus' lust. (Bracke, 2009, p. 160)

12. Especialmente en los Acarnienses (vv. 739, 764, 767, 768, 769, 771, 773, 778, 781, 788, 792, 794, 795, 800), pero también en la Asamblea de mujeres (v. 724) y en las Tesmoforias (vv. 289, 538, 540).

13. También aparece mencionado en la Asamblea de mujeres (ss. 647).

\section{Bibliografía}

Anaxímenes de Lámpsarco. (2005). Retórica a Alejandro. (D. Hernández de la Fuente, tr.). Madrid: Editorial Gredos.

Aristófanes. (1954). Obras completas. (F. Baráibar y Zumárraga, tr). Buenos Aires: Librería "El Ateneo" Editorial. 
Aristófanes. (2000). Comedias I: Los acarnienses. Los caballeros. (L. Gil-Fernández, tr.). Madrid: Editorial Gredos.

Aristófanes. (2004). Las Nubes. Las Ranas. Pluto. (F. Rodríguez-Adrados y J. RodríguezSomolinos, tr.). Madrid: Cátedra.

Aristófanes. (2007). Comedias III: Lisístrata. Las Tesmoforias. Las ranas. Las asambleístas. Pluto. (L. Macía-Aparicio, tr.). Madrid: Editorial Gredos.

Aristophanes. (1907). Comoediae. United Kingdom: Clarendon Press.

Aristóteles. (1990). Retórica. (Q. Racionero, tr.). Madrid: Editorial.

Blanc, A. y de Lamberterie, C. (2009). Chronique d'étymologie grecque n 12 (CEG 2012). Revue de philologie, de littérature et d'histoire anciennes. 83 (2), 285-325.

Bracke, E. (2009). Of Metis and Magic: The Conceptual Transformations of Circe and Medea in Ancient Greek Poetry. (Vol. I). (Tesis doctoral). Universidad Nacional de Ireland Maynooth.

Esquilo. (2008). Fragmentos. Testimonios. (J. M. Lucas de Dios, tr.). Madrid: Editorial Gredos.

Gil, L. (1993). La comicidad en Aristófanes. Cuadernos de Filología Clásica. Estudios griegos e indoeuropeos. 3, 23-39.

Herodoto. (2000). Historia. Libros VIII-IX. (C. Schrader, tr.). Madrid: Editorial Gredos.

Homero. (1998). Odisea. (J. M. Pabón, tr.). Madrid: Editorial Gredos.

Hordern, J. (1999). The Cyclops of Philoxenus. The Classical Quarterly, New Series 49 (2), 445-455.

Lesky, A. (1989). Historia de la literatura griega. Madrid: Editorial Gredos.

Liddell, H. y Scott, R. (1940). A Greek-English Lexicon. Oxford: Clarendon Press.

Liddell, H. y Scott, R. (1996). A Greek-English lexicon with a Revised Supplement. Oxford: Clarendon Press.

López-Férez, J. (Ed.). (1988). Historia de la literatura griega. Madrid: Cátedra.

Melero-Bellido, A. (1988). Tragedia: el drama satírico. Por J. López Férez (Ed.). Historia de la literatura griega. (406-430). Madrid: Cátedra.

Morales-Harley, R. (2013). Autoridad/Subversión en el Pluto de Aristófanes: un nuevo dios a la cabeza. Revista Káñina. 37 (1), 49-63.

Page, D. L. (1967). Poetae melici Graeci. Oxford: Clarendon Press.

Sancho-Royo, A. (1983). Análisis de los motivos de composición del Cíclope de Filóxeno de Citera. Habis. (14), 33-50.

Sutton, D. (1983). Dithyramb as $\Delta \rho \tilde{\alpha} \mu \alpha$ : Philoxenus of Cythera's «Cyclops or Galatea». Quaderni Urbinati di Cultura Classica, New Series. 13 (1), 37-43.

Thorburn, J. (2005). The Facts On File Companion To Classical Drama. New York: Facts on File. 